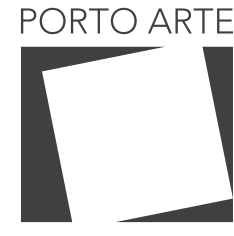

Revista de Artes Visuais

1.25 n. 44 $\mathrm{Jul} / \mathrm{dez} 2020$ e-ISSN: 2179-8001

\title{
Jorge Menna Barreto sobre restauro agroecológico, amizade e pesquisa artística
}

Jorge Menna Barreto on agroecological restoration, friendship, and artistic research

\section{Vagner Godói}

ORCID: 0000-0001-8739-5401

Universidade Estadual Paulista, Brasil

Jorgge Menna Barreto

Universidade do Estado do Rio de Janeiro

\section{Resumo}

A conversa com Jorgge Menna Barreto, artista-pesquisador e atualmente professor da Universidade da Califórnia Santa Cruz (UCSC), aconteceu no dia 9 de fevereiro de 2017, momento após sua participação na 32a Bienal de São Paulo. Para a mostra, o artista criou Restauro, um restaurante que servia pratos feitos com legumes, hortaliças, frutas e matinhos comestíveis de agroflorestas. Restauro é resultado de uma trajetória de pesquisa mais ampla, que se desenvolve a partir de questionamentos sobre as relações entre público, lugar, educação, instituição e obra de arte; a pesquisa artística e a situação do artista na academia; e sobre estratégias de site-specificity ampliadas para as relações entre paisagem, meio ambiente e alimento.

Palavras-chave:

Arte Contemporânea, Pesquisa Artística, Agroecologia, Educação como Arte,

Site-specificity

\section{Abstract}

This conversation with Jorge Menna Barreto, artist-researcher and currently professor at the University of California Santa Cruz (UCSC), took place on February 9. 2017, after the artist's participation in the 32nd Bienal de São Paulo. For the show, Barreto created Restauro, a restaurant that featured a menu of greens, fruits and other edibles produced in agroforestry systems. Restauro is the outgrowth from a broader path of research, developed on the basis of questionings into the relations between public, place, education, institution and artwork; artistic research and the situation of the artist in the academy; and discursive strategies of site-specific enlarged for the relations between landscape, environment and food.

Keywords:

Contemporary Art, Artistic Research, Agroecology, Education as Art, Site-specificity 


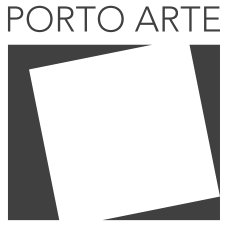

Revista de Artes Visuais

$25 n .44$

Jul/dez 2020 e-ISSN: 2179-8001

\section{Sucos específicos, agroecologia e ser vegano}

\section{Vagner Godói [ VG ]:}

Sucos específicos ${ }^{1}$ foi o primeiro projeto que você fez a respeito de agroecologia?

\section{Jorge Menna Barreto [JMB]:}

Na verdade, aconteceu no Café Educativo² de 2013, no Museu da Gravura, em Curitiba. Foi a primeira vez, de maneira um pouco acidental, digamos. 0 museu ficava do lado de uma feirinha orgânica, e eu já tinha esse interesse; então, envolvi a feirinha como fornecedora do Café Educativo. Fazia parte também desse projeto uma oficina, que tinha o título "A Relação entre as práticas site-specific e a agroecologia". Isso foi em 2013; e dei essa oficina, por sugestão do Felipe Prando, que era o curador, em uma agrofloresta no norte do Paraná, a Cooperafloresta ${ }^{3}$. Foi o meu primeiro contato... daí pirei com a ideia sobre o que é uma agrofloresta. Isso tudo resultou no pós-doutorado também. Então, tem esse antecedente; não estava superclaro ainda o que era...

VG:

Você já era vegano?

JMB:

Eu me tornei em 2011. Foi durante o doutorado, durante a pesquisa. E eu achava que era uma questão minha, uma questão biográfica, e não algo que tivesse relação com o trabalho. É engraçado quando tu escreves o doutorado ${ }^{4}$ porque... - e isso para mim é algo que não era o foco da minha pesquisa, não era o meu objeto de pesquisa, mas fazia parte da minha relação com a escrita - eu estava em uma crise muito grande. Entrando nos dados biográficos, eu estava em uma crise muito grande durante o doutorado, querendo largar; estava desanimado, como é frequente. A gente tem os períodos de desânimo. Um amigo me recomendou consultar com uma nutricionista; ao invés de ir ao psiquiatra, fui à nutricionista. E ali começou um processo de auto-observação, de começar a perceber e sair do período de desânimo. Entrei em um período de transformação do corpo, do jeito de entender o alimento. Isso começou dentro do dou-

\footnotetext{
1- Sucos verdes veganos feitos de frutas e fol has de Plantas Alimentícias Não Convencionais (PANCS) ou como prefere Menna Barreto, "matinhos comestíveis". Duzentas garrafinhas de $50 \mathrm{ml}$ foram produzidas para ser parte do encerramento do projeto Ações Curatoriais, com curadoria de Kamilla Nunes, Beatriz Lemos e Marta Mestre, na Ilha de Anhatomirim, perto de Florianópolis, em 8 de junho de 2014. Ver: BARRETO, Jorge Menna. Deixe que o lugar determine. In: MARINHO, Claudia; CAETANO, Patrícia; RIBEIRO, Walmeri Das artes e seus percursos sensíveis. São Paulo: Intermeios, 2016. p. 201-206.

2- O Café Educativo é um espaço de convívio para que as pessoas possam tomar um café, um suco, e conversar sobre a exposição com um garçom que também é mediador. A obra ocorreu pela primeira vez em 2008 no evento "Arte e Esfera Pública", no Centro Cultural São Paulo, e depois aconteceu em várias ocasiões, como, por exemplo, no $32^{\circ}$ Panorama da Arte Brasileira, em 2011

3- Cooperativa de trabalho pioneiro sobre agrofloresta, composto de famílias agricultoras quilombolas nos municípios de Barra do Turvo em São Paulo e Adrianópolis no Paraná. Agrofloresta é uma forma de criação cultivo e produção de alimentos que se integra à floresta. Diferente da agricultura artificial e mecânica, conserva os rios e o solo, não utiliza pesticidas, preocupando-se com as relações ecológicas e a biodiversidade 4- O artista fez doutorado em Poéticas Visuais na Escola de Comunicações e Artes da Universidade de São Paulo (ECA/USP), com o título "Exercícios de leitoria". A elaboração da obra Desleituras (2011) é do mesmo perío do de pesquisa de sua tese. Ver: BARRETO, Jorge Menna. Exercícios de leitoria. 2012. Tese (Doutorado em Poéticas Visuais) - Escola de Comunicações e Artes, Universidade de São Paulo, São Paulo, 2012.
} 


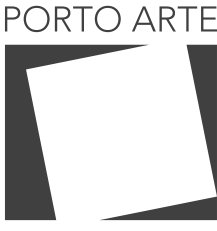

Revista de Artes Visuais

v. 25 n. 44

$\mathrm{Jul} / \mathrm{dez} 2020$ e-ISSN: 2179-8001

torado. Essa solidão profunda que a gente vive no doutorado, no momento da escrita... - especialmente quando eu fui para Porto Alegre escrever, fiquei nove meses em Porto Alegre escrevendo - então, tudo o que você come, tudo o que você faz, acaba impactando a tua produção. É um momento de autoanálise também, grande, o doutorado. Você tira o foco do seu objeto de análise, mas o modo analítico permanece contigo para tudo. Mas eu achei, inicialmente, quando estava escrevendo, que aquilo era mais uma questão pessoal que não vazou para dentro do doutorado como assunto. Assim que eu terminei o doutorado foi para isso que me direcionei. Só que daí, quando caiu a ficha de que o alimento é um dos mediadores principais da relação sociedade-ambiente, me dei conta que não estava distante de algo que me interessa, que são as questões da terra, do território, de ocupação de espaço, de uso dos lugares, uso da terra. Daí comecei a encontrar alguns aliados para pensar sobre isso, tanto dentro da discussão sobre agroecologia como em arte também. Por exemplo, revisitando os projetos de Land Art, de intervenção na paisagem; um livro que foi importante também para eu entender isso foi o Undermining ${ }^{5}$, da Lucy Lippard, último livro dela, que eu pesquisei durante o pós-doc. É um pouco sobre pensar as intervenções ambientais como parte de um sistema não só de intervenção intencional na paisagem, mas dos nossos hábitos enquanto sociedade. Eu acho que isso soluciona a questão que ela traz: como o nosso modo de viver, de estar, cria um impacto ambiental e modela a paisagem; então, essa ideia eu trago dela, só que partindo do processo digestivo, da relação com o alimento.

\section{Sobre artivismo e o coletivo laranjas}

\section{VG:}

Você está falando dessas questões que adentram um campo político. Eu acho que a sua obra antes estava pautada pelo político ou pelo ativismo, mas de forma um pouco mais branda. Talvez agora tenha ficado um pouco mais forte. Os anos 2000 foram de ativismo muito intenso, a partir do Fórum Social de 2001, em Porto Alegre ${ }^{6}$, e um número grande de artistas brasileiros começou a trabalhar sobre questões sociais ou políticas, e você faz parte desse momento. Queria que você contasse um pouco desse percurso dentro do seu trabalho e também da ação feita no Fórum Mundial, em que você tapou buracos, porque não encontrei muita coisa a respeito disso. Nem sei se você considera como uma obra ou se dentro do seu percurso. E como seria essa ponte política até agora?

\footnotetext{
5- LIPPARD, Lucy R. Undermining: A Wild Ride Through Land Use, Politics, and Art in the Changing West. Nova York: The New Press, 2014 


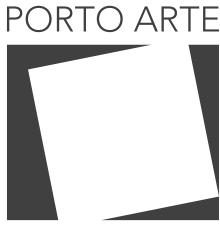

Revista de Artes Visuais

V.25 n.44

Jul/dez 2020 e-ISSN: 2179-8001

JMB:

Ah, legal, legal resgatar isso. Eu fazia parte de um coletivo que se chamava Laranjas $^{7}$. Ali, no início da década passada [década de 2000], foi um momento de coletivização, não só em Porto Alegre onde eu morava, mas também em vários lugares do Brasil. Os artistas estavam se juntando para fazer coisas, e que não dependessem necessariamente de um amparo institucional. Um artigo da Juliana Monachesi, que saiu na Folha, buscou mapear alguns desses coletivos $^{8}$; talvez tenha sido a primeira vez que vi a palavra artivismo. Ela junta arte com ativismo e busca pensar a relação desses coletivos com o âmbito institucional também, e eu também contribuo para esse artigo. Isso foi muito próximo da minha saída de Porto Alegre; comecei a fazer o movimento de sair de Porto Alegre para fazer o mestrado aqui em São Paulo, em 2002. Foi quando eu comecei a fazer umas disciplinas como ouvinte com a Sônia Salzstein. Eu já vinha de uma reflexão, desde a minha graduação, sobre as práticas site-specific. A graduação eu terminei em 1997; então, o trabalho Minha Terra, Sua Terra ${ }^{9}$, por exemplo, que é de 1999, já tinha uma reflexão e uma ideia sobre o lugar, sobre a terra, sobre o chão, a partir de uma condição nômade, uma condição que não é fixa, que eu fui analisar só mais adiante, lá no mestrado ${ }^{10}$. Essa ação no Fórum Mundial foi noturna, onde busquei alguns buracos no trajeto entre a minha casa e onde o Fórum acontecia. Eu fiz uma mistura com gesso cor de laranja...

\section{VG:}

Mas junto com os Laranjas?

JMB:

Foi uma ação minha, mas impregnado pelos Laranjas. Foi uma questão que a gente discutiu, o quanto o estado Laranja é um estado molecular. A gente não precisava estar em grupo pra atuar como um Laranja; é a própria ideia de coletivo... Tem um texto que escrevi sobre isso, de 2008, uma reflexão sobre uma exposição na qual os Laranjas participaram no Maria Antônia ${ }^{11}$. Uma ação coletiva reside em um agrupamento de

\footnotetext{
7- Grupo Laranjas, coletivo originário de Porto Alegre. Fez parte Cristina Ribas, Jorge Menna Barreto, Cristiano Lenhardt, Fabiana Rossarola, Adriana Boff, Denise Gadelha e Patricia Francisco, que existiu, mais ou menos entre 2001 e 2008, não necessariamente formado por todos até o final. Os Laranjas vestiam macacões laranjas, como os dos trabalhadores da prefeitura.

8- Ver: MONACHESI, Juliana. A explosão do a(r)tivismo. p. 4-9. Folha de S. Paulo, Mais!, p. 4-9, 6/4/2003 Disponivel em: <www1.folha.uol.com.br/fsp/mais/fs0604200305.htm>. Acesso em: 2 out. 2017. 9- Minha Terra, Sua Terra (MTST), de 1998, consiste em oferecer porções de terra, embalada em saquinhos, ao público da exposição. A terra era transportada de Porto Alegre, cidade do artista na época, para as cidades em que essa obra foi exibida, como São Paulo, Salvador, Belém. Florianópolis, Rio de Janeiro, Caracas e Belo Horizonte. A obra foi imaginada inicialmente para o Linha Imaginária, um projeto de intercâmbio de artistas e exposições criada por Sidney Philocreon, bastante atuante na década de 2000.

10- Jorge Menna Barreto é mestre em Poéticas Visuais pela Escola de Comunicações e Artes da Universidade de São Paulo (ECA/USP). Com o título "Lugares moles", a dissertação, defendida em 2007, coloca a noção de site-specific como estratégia e método das obras feitas pelo artista até então. A partir daí, o lugar específico expande-se para uma condição de espaço discursivo, em que até uma dissertação de mestrado transforma-se em lugar e obra de arte. Ver: BARRETO, Jorge Menna. Lugares moles. São Paulo, 2007. Dissertação (Mestrado em Poéticas Visuais) - Escola de Comunicações e Artes, Universidade de São Paulo. 11- MENNA BARRETO, Jorge. Exposição Campo coletivo: curadoria de Fernanda Albuquerque e Gabriela Motta. Fórum Permanente, 2008. Disponível em: <http://www.forumpermanente.org/event_pres/cursos-disciplinas/disciplina-cap5937-intervencoes-urbanas-no-espaco-publico/relatos-eca/exposicao-campo-coletivo-curadoria-de-fernanda-albuquerque-e-gabriela-motta>. Acesso em: 25 jan. 2016.
} 


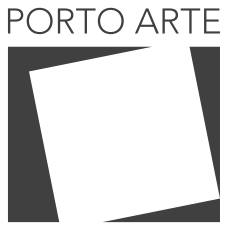

Revista de Artes Visuais pessoas que são propositoras, mas pode residir também como metodologia de trabaIho, com várias pessoas envolvidas. E um trabalho que considero coletivo, apesar de ser feito muitas vezes sozinho, e que uso no texto, é justamente um trabalho da Carla Zaccagnini.

VG:

Que inclusive se chama Restauro ${ }^{12}$.

JMB:

Sim, exatamente. 0 trabalho do CCSP.

VG:

Não tem nenhuma relação?

JMB:

Com o Restauro da Bienal? É um trabalho que me interessa muito, ele me ocupou; conversei com a Carla a respeito do Restauro. É um trabalho que me habita.

VG:

Mas não foi uma homenagem direta ou...

JMB:

Não, é um outro jeito de chegar no título... Eu acho que tem algo da relação com a história de ser um restaurante. Tem uma coisa que talvez tenha sido mencionada na banca [de defesa do mestrado de Carla Zaccagnini ${ }^{13}$ ] sobre o artista como aquele que faz uma benfeitoria na instituição, uma crítica institucional que vem como uma ajuda, quase, como uma melhoria. Não são palavras adequadas as que estou usando, mas ali tem uma ideia de restauro, que não é da obra Cabeça, do Almeida Junior, mas que é de um restauro do CCSP; é uma prática restaurativa. Eu acho que aí sim tem uma conexão, porque eu entendo que o Restauro presta serviço institucional, ao mesmo tempo que se coloca de maneira crítica ou aponta que ali tem um espaço que está adormecido, que não tem sido pensado dentro, que se constitui como fora, mesmo estando tão dentro arquitetonicamente, espacialmente; mas que também inclui os educadores. Pela primeira vez os educadores e os funcionários da Bienal têm um lugar para comer, porque era algo que não acontecia nos restaurantes anteriores, pelo preço, pela qualidade da comida.

\footnotetext{
12- A obra Restauro, de Carla Zaccagnini, de 2001, consistiu na restauração de um quadro de Almeida Junior, que faz parte da reserva técnica do Centro Cultural São Paulo (chamada "Pinacoteca Municipal de São Paulo"), um pequeno óleo sobre tela, de 1822, intitulado Cabeça. Além do quadro exibido no Centro Cultural São Paulo, um folder foi disponibilizado, com um texto da artista baseado na entrevista com as restauradoras do quadro, revelando um pouco sobre os "bastidores da negociação" ou as "camadas textuais" envolvidos no processo de Restauro.

13-ZACCAGNini, Carla. A obra como lugar do texto, o texto em lugar da obra. São Paulo, 2004. Dissertação (Mestrado em Poéticas Visuais) - Escola de Comunicações e Artes, Universidade de São Paulo. p. 106-107. No texto, Zaccagnini faz a leitura de quatro obras suas realizadas entre 2001 e 2004: Restauro, Panorama, Bibliografia e da própria Dissertação, também uma Obra de Arte.
} 


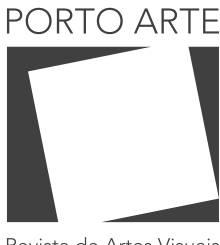

Revista de Artes Visuais

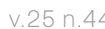

\section{A criação de um restaurante}

VG:

O valor era baixo. Pelo valor do almoço que é cobrado aqui em São Paulo... Isso era subsidiado? Se sustentou?

JMB:

Não era subsidiado, parte da nossa ideia era de que o restaurante fosse sustentável. Era muito importante. Sustentou e até deu um excedente, que a gente pretende usar para fazer a publicação. Tinha umas estratégias; a gente tinha uma economista na equipe. Ela nos ajudou a pensar algumas questões a partir dessa ideia da economia solidária, que era um pouco de poder optar pelo preço. Mesmo o preço mais alto era um preço barato, mesmo 15 reais era barato. A gente tinha, por exemplo, a água, que era 5 reais... o refresco também. Então, a gente tinha produtos que subsidiavam o almoço. Quem tinha grana só para almoçar não entrava nos excedentes. Tinha gente que chegava lá e dizia "ah eu quero tudo" e gastava... sei lá, gastava mais. Então essas pessoas acabavam sustentando ou possibilitando a participação de todo mundo. Não foi um excedente grande; não era um projeto orientado por lucro.

VG:

Você achou delicado fazer um trabalho que tratasse de lucro, de empresa?

JMB:

Achei superdelicado, achei superdifícil isso. É uma novidade total para mim. Pensar em uma participação que envolva economia. E pessoas trabalhando, contratadas. Todos tinham salário; sobre o salário a gente também chegou a uma decisão de que existia uma isonomia, todo mundo era pago com a mesma quantidade, mesma quantia. Era um salário baixo, mas todos ganhavam o mesmo valor, independente do que faziam.

VG:

E como foi essa negociação com a Bienal ou com o curador para que esse comércio acontecesse, porque acabou acontecendo uma obra como comércio.

JMB:

A Bienal nunca colocou isso como um problema. Foi tratado com uma naturalidade que eu até estranhei. A preocupação era mais minha.

VG:

Porque talvez eles teriam que contratar esse trabalho de qualquer jeito, seria feito por alguém. 


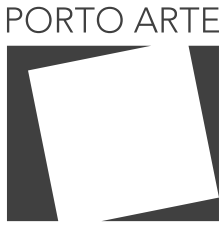

Revista de Artes Visuais

v. 25 n. 44

$\mathrm{Jul} / \mathrm{dez} 2020$ e-ISSN: 2179-8001

JMB:

Sim, seria feito por alguém. Se eu não tivesse reivindicado aquele espaço, aquilo teria sido como sempre foi; vai alguém que não é um artista, que não é uma proposta. o que eu digo é que foi tratada com uma naturalidade mas não é que não tenha sido endereçada. Foi endereçada, mas com muito menos conflito do que eu imaginei. Até porque eu acho que tinha algo que sustentava essa ideia de optar por... em determinado momento eu tive que optar: "será que eu vou fazer um quiosque vegano no terceiro andar, independente do restaurante?", e daí ser uma opção para a pessoa ir, participar e trabalhar em uma escala outra, em uma escala artesanal, com horários que a gente definiria de atendimento e de cair dentro de uma situação que é mais simbólica, talvez, do que de impacto real. Ou se a gente vai de fato ter uma intervenção, que ela é, no sistema estrutural da Bienal, em um esqueleto da própria fundação, no seu modo de funcionamento, e reverter isso para uma chave que seja de um impacto ambiental positivo. E, logo de saída, a gente se deu conta de que se quisesse trabalhar com insumos agroflorestais e, de fato, ter um impacto importante e significativo nessas redes com quem a gente gostaria de trabalhar, não poderia ir a esses assentamentos e pedir um saco de tomate... A escala também foi ditada pelo tipo de impacto e incentivo que a gente queria nesses nossos fornecedores. E também a dimensão econômica; pensar a dimensão econômica como impacto ambiental. Porque logo nas nossas primeiras visitas às agroflorestas, ficou claro que a forma de impacto que a gente teria nessas famílias seria via economia, via aquisição de produtos. Logo que me convidaram eu manifestei meu desejo de trabalho com a agrofloresta, mas não sabia como.

\section{VG:}

Até então você não tinha a ideia de ocupar o espaço do mezanino?

JMB:

Não, isso veio depois. Então, eu fiquei pensando muito no [Robert] Smithson, na ideia de site e non-site, pensando agrofloresta como um lugar remoto e de como trazer isso para Bienal. Então, pensei nas linguagens mais familiares à arte e ao próprio Smithson; em filme, pensei em gravação da paisagem sonora; pensei em texto, pensei em uma publicação. Até que cheguei nessa ideia do alimento como mediador dessa relação. Mais do que pensar em uma ideia de representação da floresta dentro do pavilhão, pensei que o alimento poderia dar conta dessa extensão. De pensar a Bienal como uma extensão da floresta e como parte de um sistema que tanto a agrofloresta alimenta a Bienal, como a Bienal, a partir de uma dimensão econômica, retroalimenta essas famílias que foram as fornecedoras. Então, a dimensão econômica se faz presente por uma necessidade de alimentar esse sistema.

\section{VG:}

Algumas coisas tiveram que ser criadas, ou vocês pegaram modelos, de um restaurante vegano, por exemplo? 


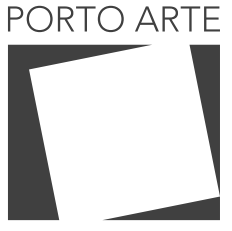

Revista de Artes Visuais

JMB:

Não, foi tudo criado do zero. Essa rede de agrofloresteiros não existe.

VG:

Esse modelo de negócio. (risos)

JMB:

Não, isso era um desafio até para a escola de ecogastronomia, que era uma das colaboradoras. Elas queriam de fato ter um modelo de negócio que pudesse inspirar outros restaurantes; provar que é viável e próspero. Então, isso era um objetivo delas.

VG:

E tem restaurantes que têm esse mesmo modelo?

JMB:

Não, essa rede de abastecimento não estava pronta, ela foi construída do zero, com todas as dificuldades possíveis de escala, de negociação econômica. Foi todo um processo inaugural; até porque, se for pensar a lógica de uma agrofloresta, não é uma lógica de abastecimento de um restaurante. A lógica de abastecimento de restaurante é mais próxima da monocultura do que da agrofloresta.

VG:

Mesmo esses restaurantes que só trabalham com orgânicos?

JMB:

Sim, sim. Eles estão ligados ao Box da Luciana no Ceagesp [em São Paulo]; a um tipo de estruturação e uso da terra, que é determinado por receita, por exemplo. Então, essa ideia de que a gente pode ter um restaurante que não tem uma receita fixa, que o alimento é determinado pelo produtor, já que a ideia de agrofloresta é muito mais para autossustentação. Então, a ideia não é de produção em escala. 0 alimento produzido é para a família que cultiva ou para o grupo que cultiva aquele espaço; o excedente é trocado com os vizinhos ou comercializado, não é uma prática de escala. E isso para nós foi resolvido - e a gente queria e insistiu que tivesse essa ênfase na agrofloresta quando a gente trabalhou com cooperativas. Então, era pego um pouco de cada família para constituir um montante que era necessário para o restaurante.

\section{VG:}

Desculpa eu te cortar para falar de uma educadora. No dia em que eu fui almoçar no Restauro, não sei se era proposital ou não, ela veio conversar com uma naturalidade... Ela, na verdade, não veio conversar comigo, especificamente. Tinha mais gente na mesa, e ela abordou as pessoas em uma conversa muito natural. De repente ela começou a falar, e eu fui percebendo que era a mediadora. Achei até que ela estava almoçando junto. Então, imagino que deve ser proposital esse tipo de abordagem. 


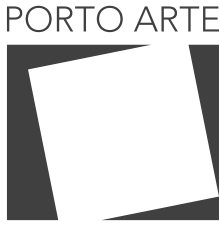

Revista de Artes Visuais

$\vee 25 n .44$

$\mathrm{Jul} / \mathrm{dez} 2020$ e-ISSN: 2179-8001

JMB:

É, foi um trabalho bem intenso para a gente entender qual era a posição desses educadores. A gente tinha duas formas de entender esse trabalho deles. A ideia de ter os educadores no salão foi muito a partir do Café Educativo, então é uma herança do Café Educativo ${ }^{14}$. No Restauro especificamente, a gente pensava que esses educadores eram como enzimas digestivas do processo de elaboração que acontecia ali. Não só uma enzima digestiva do Restauro mas também da exposição. Então, eles fizeram o curso de formação, o que os tornava aptos a conversar sobre a Bienal, entendendo que o restaurante é também um lugar de digestão da Bienal como um todo, e não só das questões propostas pelo Restauro. Então, é um lugar de metabolização do que acontece. Eu acho que isso é uma coisa enfatizada no Café Educativo, o de pensar esse momento do cafezinho como um momento de elaboração daquilo que foi visto ou de metabolização. E, outra, a gente conversava muito sobre isso, não havia algo que o público deveria sair sabendo dali. A obra não precisava ser completada pelo discurso do educador. Se a pessoa saísse sem saber que era uma obra, só quis tomar um café, como exemplo que eu dei, está tudo certo.

\section{VG:}

Eu percebi que não tinha educador em todas as mesas. Acho que tive a sorte de cair em um momento em que aconteceu uma mediação.

JMB:

Não tinha uma regra; por conta disso, é um pouco aleatória a atuação deles, e eles também trabalhavam com a recepção das escolas que visitavam. Por isso também eram pagos pela Bienal, porque isso foi uma questão que a gente não completou. As degustações para as escolas eram pagas pela Bienal e fornecidas pelo Restauro. Então, havia, sim, um subsídio pra ter esse acesso das pessoas que ou não podiam fazer uma refeição, porque não podiam pagar nem os 15 [reais] - apesar de ser barato, tem gente que não pode - ou pelo tempo também restrito só ficavam 10, 15 minutos ali. Então, a gente tinha degustações públicas para as escolas. E daí os educadores ajudavam com isso; mas também com público espontâneo. Algo que pautava também a atuação deles, algo que a gente conversou, era tentar perceber qual a era fome das pessoas que estavam por ali. A fome foi uma palavra que a gente usou, mas qual era a biodisponibilidade de cada um para uma abordagem mais discursiva? E aí era muito da sensibilidade de cada educador, de chegar e ver o quanto cabe uma conversa e o quanto não cabe, o quanto há de interesse com quem eles estão conversando e quanto que não há. Mas isso era bem importante, de não ter esse conteúdo preparado para delivery.

14- Para saber mais sobre a obra Café Educativo, de Menna Barreto, e sua relação com o fenômeno da educação nas artes, ver: GONÇALVES, Mônica Hoff. A virada educacional nas práticas artísticas e curatoriais contemporâneas e o contexto de arte brasileiro. Porto Alegre, 2014. Dissertação (Mestrado - Programa de Pós-Graduação em Artes Visuais), Universidade Federal do Rio Grande do Sul. 


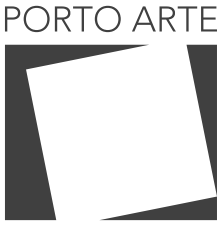

Revista de Artes Visuais

$\vee 25 n .44$

$\mathrm{Jul} / \mathrm{dez} 2020$ e-ISSN: 2179-8001

Sobre a incompreensão da pesquisa artística na $32^{a}$ bienal de são paulo

VG:

Tem uma questão dessa última Bienal [ $32^{\mathrm{a}}$ Bienal de São Paulo] - acho que é uma questão bem complexa, imagine, até de a gente imaginar agora - que foi a incompreensão daqueles trabalhos pelos críticos Aracy Amaral, Sheila Leirner, Rodrigo Naves, geralmente publicadas pelo Estadão. Nessa Bienal ficou muito forte e muito presente a pesquisa artística. E ao meu ver essa incompreensão é uma incompreensão também do fenômeno da pesquisa artística hoje. Parece que houve uma simplificação dessas novas práticas artísticas e uma visão desses críticos muito reducionista, muito simplista, querendo fazer uma associação dessas práticas novas com as dos anos $1960 \mathrm{e}$ 1970. Queria saber como você vê essa incompreensão. É algo que sempre aconteceu, mas o nome (principalmente na Europa) está sendo definido agora. No Brasil bem antes. 0 modo como acontece hoje é bem específico, tem um modo diferente.

JMB:

Superlegal essa tua observação, eu não tinha pensado a partir dessa perspectiva da pesquisa artística. Acho que coloca alguns desafios para o formato expositivo, mesmo. 0 que o formato expositivo pode ser? Quais são as qualidades do formato expositivo que dão conta de uma pesquisa artística? Considerando que muitos desses trabalhos demandam um tempo de leitura e de aproximação que, às vezes, o formato expositivo não oferece. 0 conforto ou o tempo mais dilatado de permanência com a obra. Eu posso te responder, mas a partir do meu caso. Adoraria revisitar agora a Bienal a partir dessa perspectiva que tu colocas. Mas eu acho que ali no caso do Restauro tem essa vantagem, entre aspas, de ser um espaço de permanência. Por mais que as refeições sejam feitas de maneira mais rápida, 15 ou 20 minutos, em uma obra é bastante. Se a gente for pensar que o hábito de visita de uma obra é muito menor, o tempo de permanência em um determinado trabalho, acho que ali no Restauro tinha essa dilatação do tempo que é positiva para entrar em contato com o trabalho que demanda mesmo um pouco mais de envolvimento; para que você acesse o que ali tem de pesquisa. Também pensando nos desafios de expor uma pesquisa. O Restauro começou no pós-doc e a pesquisa é algo contínuo. Na Bienal anterior, teve um recorte possível, que foi o Sucos Específicos e agora tem o Restauro. Como se desse fluxo de rio a gente fizesse um recorte, tirasse isso e trouxesse para uma dimensão de exposição; esse fluxo de rio é constante. A exposição não necessariamente é o objetivo da pesquisa; ela é um momento de visibilidade daquela pesquisa. Então, eu também entendendo que uma publicação seria quase uma itinerância do Restauro para um ambiente impresso, como se a gente fosse itinerar mesmo a obra. Não é uma obra sobre o Restauro.

VG:

Não é uma documentação? 


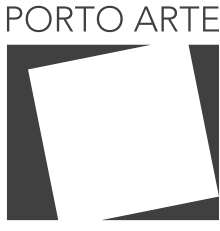

Revista de Artes Visuais

v. 25 n. 44 $\mathrm{Jul} / \mathrm{dez} 2020$ e-ISSN: 2179-8001

JMB:

Não. Não como eu estou pensando agora. Não gostaria que fosse algo documental, mas algo como uma extensão mesmo. Pensar que isso faz parte de um sistema mais complexo que envolve todos esses agentes: pós-doc, Restauro, os Sucos Específicos etc. A possibilidade de olhar para isso de uma maneira sistêmica; daí se você entende que as pesquisas também são sistêmicas, cada pesquisa de cada artista envolvido, isso demanda também um repertório sobre cada artista, sobre a forma de expor e sobre os assuntos traçados. Só a mediação, o catálogo e o ambiente expositivo não dão conta.

\section{VG:}

Mas mesmo para um crítico de arte?

JMB:

É, eu acho que é criticável, não é? A Paula Braga faz uma crítica da crítica ${ }^{15}$. Eu tendo a trazer para uma autocrítica também, de pensar: "poxa, mas como criar". A Bienal é um ambiente que dita um tipo de visitação; quer dizer, imagina quantas Bienais a Aracy Amaral já não viu. E tudo isso que ela viu dita a forma como ela vai ver essa Bienal e o que se espera também de uma Bienal; então, eu acho que faz parte de um hábito que a gente adota. Fazer a exposição dentro do pavilhão da Bienal... a gente necessariamente tem que lidar com tudo isso que está construído naquele espaço, que está determinado por aquele espaço, por aquele hábito. Eu acho que o bacana é a gente fazer uma reflexão sobre isso, sobre essas limitações do prédio, as limitações do formato expositivo, fazer uma crítica das estratégias curatoriais e educativas.

\section{Metodologia da amizade}

VG:

Em muitos momentos, a participação que você propõe é de amizade. Às vezes até de amizade eletiva, de afinidades eletivas, de pessoas que possam travar um vínculo de amizade, um vínculo artístico, uma amizade nova ou uma amizade que já vem há muito tempo, se desdobrado no tempo; ou a amizade que acontece só no momento da participação mesmo. Como é essa questão da amizade dentro do seu projeto poético?

\section{JMB:}

Eu não sei se eu... Teria que pensar mais sobre isso, eu acho.

\section{VG:}

Se você quiser falar alguns pontos onde isso... Ou se isso aconteceu. Talvez seja uma coisa que eu tenha verificado, mas...

\footnotetext{
15- O texto fala sobre as críticas de Aracy Amaral, Sheila Leirner, Rodrigo Naves, Ferreira Gullar, entre outros. Ver: BRAGA, Paula. A crítica da crítica. Uma reflexão sobre as críticas da $32^{a}$ Bienal de São Paulo publicadas pelos jornais de grande circulação. Revista Select, São Paulo, 15 jun. 2016. Disponível em: <http:// www.select.art.br/ 


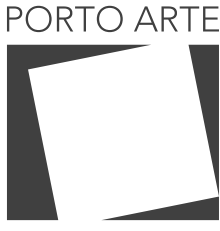

Revista de Artes Visuais

$\vee 25 n .44$

$\mathrm{Jul} / \mathrm{dez} 2020$ e-ISSN: 2179-8001

JMB:

Sim, sim... É, eu acho que tem algo; tem uma dimensão afetiva. E daí entendendo a ideia de afeto não dessa ideia do emocional, mas da possibilidade de afetar e ser afetado, da possibilidade de estabelecimento de um território de afetações, de troca de afetos que eu acho que é muito talvez da maneira como eu entenda a participação mesmo. Eu acho que existem questões que passam por motivação. Como motivar alguém para participar? Como convocar? Ou seduzir também? Ou capturar? Então, eu entendo isso a partir do campo de afetos; mas uma reflexão que para mim não é algo completamente que eu aplique de forma direta. É um texto do Francisco Ortega ${ }^{16}$, que até foi o [Ricardo] Basbaum que me passou. Ele fala da amizade como uma construção desse campo político que não é o campo familiar. Amizade como possibilidade de manutenção de um campo que é político. A amizade que te daria o distanciamento necessário que é suprimido pelas relações familiares ou pela familiarização das relações: isso de a gente tratar o amigo como um irmão e de, às vezes, suprimir essa distância. Então, ele fala dessa distância que existe na amizade como sendo algo a ser cultivado. Essa dosagem por vezes eu encontro de forma melhor e outras de forma mais... Acho que nem sempre eu consigo que esse território da amizade seja mantido como um território político. Acho que é uma eterna tentativa de estabelecer... Mas que por vezes depende da temporalidade de cada um. No Restauro, foram muitas as respostas que a gente teve do público. Porque eu estava ali atendendo quase que o tempo todo; foi um momento de muita observação, de ver como cada um se relacionava com a proposta. Teve gente que vinha encantada pela comida e dizia assim: "nossa, é verdade, isso aqui é uma obra de arte". Daí olhava para o prato e pensava que a visualidade do prato era o que justificava aquilo ser uma obra. Ou por causa da bandejinha, sabe? Tinha esses lances de design e de apelo visual do trabalho que, por vezes, confundiam o público, de trazê-lo para uma dimensão que é mais reconhecível a partir do design ou da gastronomia como arte. Então, isso foi um risco que a gente sentiu, na forma como a gente abordou, e isso foi uma questão que o Jochen [Volz, curador da $32^{\mathrm{a}}$ Bienal] trouxe no início, quando a gente estava pensando nos móveis e em como espacializar isso tudo. Ele falou para a gente ter cuidado para que isso não virasse a arte do trabalho. Então, como que a gente pode ser econômico e enxuto e seco suficiente para que a obra esteja nesse outro lugar que a gente gostaria que ela estivesse? Mas eu acho que isso diz respeito a estratégias de vinculação à obra. E, ali, por ser um restaurante que acolhe todos os públicos, eu achei que era importante a gente lançar mão dessas estratégias, de uma captura que também partisse desse sensorial mais imediato, de ter um prato bem bacana, bem construído. Não acho que tenha sido excessivo nesse sentido, não acho que tenha sido um ambiente artistificado. Mas de não abdicar dessa questão, como já abdiquei em outros trabalhos.

\footnotetext{
16- Textos do pesquisador espanhol Francisco Ortega, professor do departamento de Ciências Humanas e Saúde do Instituto de Medicina Social da Universidade do Estado do Rio de Janeiro (IMS/UERJ). Ver: ORTEGA, Francisco. Genealogia da amizade. São Paulo: Iluminuras, 2002; Para uma política da amizade: Arendt. Derrida, Foucault. Rio de Janeiro: Relume-Dumará: 2000, e Amizade e estética da existência em Foucault. Rio de Janeiro: Graal, 1999.
} 


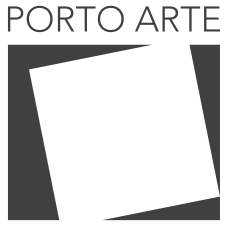

Revista de Artes Visuais
VG:

O design era d'O Grupo Inteiro ${ }^{17}$ ? Todo o design?

JMB:

Não, só os móveis. 0 design foi da própria equipe de design da Bienal.

VG:

Ah é? Que planejou as caixas...

JMB:

É, tudo em colaboração comigo. Meu namorado, que é designer, participou também. A caixinha, o logo, o cartãozinho... tudo foi ideia nossa, que a gente lançou e eles resolviam isso a partir das ferramentas do design. Então, foi um processo de cocriação.

\section{VG:}

Esse processo de cocriação... em vários momentos tem vários amigos, que eu imagino que sejam amigos seus, colaborando no trabalho. Sejam amigos novos, que talvez você tenha feito, por exemplo, com as questões da agroecologia e mesmo os artistas que te acompanham desde os Laranjas, por exemplo, desde a época da faculdade, pessoas que desde aquela época duram na sua trajetória como artista também ${ }^{18}$. Eu queria saber se você considera o que eu estou chamando de amizade um método de trabalho artístico. Quando você colabora ou quando outros artistas colaboram com você.

JMB:

Sim... Eu acho bonita essa ideia da amizade. Eu gosto muito de pensar a amizade e também interespécies ou interingredientes. Quando o Smithson, fala aquela frase célebre, e sempre volto para ela, quando ele se refere ao Spiral Jet, dizendo: "Naquele momento, eu ainda não tinha certeza a respeito da forma que meu trabalho iria tomar. Eu pensei em fazer uma ilha com a ajuda de barcos e barcas, mas no final eu deixaria que o site determinasse o que eu construiria"19. Então, para mim, nessa frase tem o coração do que são as práticas site-specific, que é essa possibilidade de você retirar o outro - seja o outro quem for, nesse caso era o lago, era um espaço físico - de uma condição de suporte para criar um estado em que ele é colaborativo. Eu passo a colaborar com o espaço. E com isso também eu me coloco em uma posição que é de escuta,

\footnotetext{
17- Grupo que mistura arte, arquitetura, design gráfico em projetos de convívio, cocriação e participação, composto por Carol Tonetti, Cláudio Bueno, Ligia Nobre e Vitor Cesar. Ver: http://ogrupointeiro.net/. 18- A amizade em rede é uma das linhas de pensamento da obra Con-fio, de Jorge Menna Barreto, de 1998 parte da exposição-projeto Remetente, que aconteceu em Porto Alegre. São tijolinhos de cobre, feitos para serem levados para casa pelo público da exposição. O participador também levava uma folha com uma lista atualizada de nomes das pessoas que levaram o tijolinho anteriormente a ele. Havia tijolos com a palavra "Con" e outros com "Fio".

19- 0 trecho é citado no texto "Consciência Contextual", página 193 da dissertação Lugares moles do artista. No original: "At that point I was still not sure what shape my work of art would take. I thought of making an island with the help of boats and barges, but in the end I would let the site determine what I would build...". Ver: SMITHSON, Robert. The Spiral Jetty. In: KEPES, Gyorgy (Ed.). Arts of the Environment. Nova York: George Braziller, 1972
} 


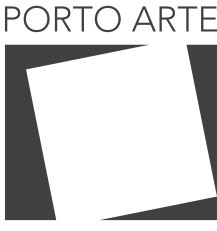

Revista de Artes Visuais

v. 25 ก. 44

$\mathrm{Jul} / \mathrm{dez} 2020$ e-ISSN: 2179-8001

que é anterior a minha ação, a minha fala. Eu acho que o bacana nessa tua pergunta, tentando imaginar que talvez essa ideia de metodologia de trabalho passe pela amizade, é entender a amizade dentro de uma perspectiva sobre-humana. No Restauro, por exemplo: uma amizade, um comer em aliança com a natureza ou em aliança com as plantas. Pensar um tipo de uso da terra que é também mais amigável com todas as espécies que ali habitam. Nessa possibilidade de criação de uma rede de afinidades que é baseada na escuta. Eu acho que talvez essa seja uma chave para juntar o meu mestrado e o meu doutorado. Se, de uma certa maneira, no doutorado, atualizo o que eu chamei de uma metodologia site-specific para pensar outros autores, de como eu me relaciono com João Cabral [de Melo Neto], de como que me relaciono com Felix Gonzalez-Torres, de como que eu me relaciono com [Hélio] Oiticica, ou com a Lina [Bo Bardi]. Talvez o que se mantenha seja isso, seja uma metodologia de trabalho baseada em vínculos de amizade. No doutorado, eu coloco isso de maneira bem clara, que não são vínculos de adesão à poética alheia, mas que envolvem também confrontos, envolvem fricções, envolvem negociações e até desamizades, se a gente for fazer uma atualização da ideia de Desleituras. Mas eu acho que isso também pode ser uma possibilidade de leitura desse método, pode ser um método de leitura, de ler aqueles que constelam junto comigo... uma geração. Acho que o Rumos ${ }^{20}$ foi muito importante para me inserir em uma rede de pessoas. O Rumos foi bem importante; foi onde eu conheci a Graziela Kunsch, o Marcelo Cidade, o Alexandre Vogler, o Ducha, a Cristina Freire, o Fernando Cocchiarale. Eu não criei obras novas, fiz uma extensão do Massa ${ }^{21}$ que eu tinha feito em Havana. Então itinerei com o Massa para Fortaleza, Belo Horizonte, São Paulo; a cada cidade, eu somava também os pesos, eu retomava do peso que eu tinha deixado na cidade anterior. O Minha Terra, Sua Terra, na curadoria da Marisa Flórido, eu refiz em Belo Horizonte.

VG:

Esse Rumos 2 especificamente teve uma liberdade muito grande...

JMB:

Muito, muito grande. Trabalho muito próximo de amizade dessas pessoas, tanto dos curadores quanto dos artistas. A gente era enquadrado, e os curadores definiam

\footnotetext{
20- A Edição 2001/2003 do programa Rumos Itaú Cultural Artes Visuais fez um mapeamento nacional da produção emergente à época, com coordenação-geral de Fernando Cocchiarale, a ajuda de três curadores-coordenadores, Cristina Freire, Moacir dos Anjos e Jailton Moreira, além de nove curadores-adjuntos que ajudaram a fazer o mapeamento. Uma mostra com todos os artistas aconteceu no Palácio das Artes de Belo Horizonte no começo de 2002 e mais quinze outras mostras ocorreram em outros espaços culturais espalhados pelo Brasil. Jorge Menna Barreto participou de dois núcleos. "Arte: Sistema e Redes", com curadoria de Cristina Freire, exibindo a obra Massa. Participaram também desse núcleo Alexandre Vogler, Carla Zaccagnini, Cinthia Marcelle, Marilá Dardot, Rosana Ricalde, entre outros. O núcleo Sobre(A)ssaltos, com curadoria de Marisa Cesar Flórido, exibiu Minha Terra/Sua Terra. Participaram além de Jorge Menna Barreto, Alexandre Vogler, Carla Linhares, Ducha, Felipe Barbosa, Graziela Kunsch, Marcelo Cidade e Rosana Ricalde.

21- Massa foi criada para a $7^{\text {a }}$ Bienal de Havana em 2000 e consistiu na distribuição para o público de sacolinhas feitas de papel kraft, sendo o principal ponto de distribuição o Centro Wifredo Lam. O peso de cada participante somado ao peso dos participantes anteriores era carimbado com um carimbo de números na sacolinha. A obra foi refeita em Belo Horizonte, São Paulo e Fortaleza, acumulando a marcação do peso total das mostras anteriores.
} 


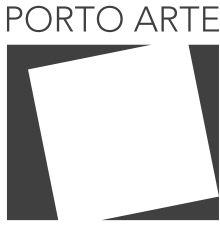

Revista de Artes Visuais

v. 25 n. 44 $\mathrm{Jul} / \mathrm{dez} 2020$

em quais núcleos que a gente participaria. Então, eu participei do núcleo da Cristina Freire, que era "Arte: sistema e redes". E dentro desse núcleo tinha outros artistas; acho que eram vinte e tantos artistas nesse núcleo. E um núcleo menor, que era o "Sobre(A) ssaltos", da Marisa Flórido. Aí eu estava com a Graziela Kunsch, o Marcelo Cidade, o Vogler, o Ducha e a Carla Linhares.

\section{VG:}

Mas você estava falando da amizade que isso foi...

JMB:

É, eu acho que isso foi bem importante. Eu acho que o meu trabalho como educador e como professor passa por aí também. Assim, como construção de contexto, um contexto de atuação, seja pelo fortalecimento das instituições, seja das relações. Eu acho que tenho como referência a minha irmã, a Lia Menna Barreto, que é da década de 1980. Nessa época tinha um tipo de atuação que era mais baseada na figura autoral, com uma assinatura de artista. Para um processo de atuação visto na década de 1990 e 2000, uma geração seguinte, de artistas que já operam em bandos.

VG:

Ou o próprio projeto de obra acaba sendo feito com a colaboração de outras pessoas...

JMB:

Sim, sim. Sendo que tem exceções. Porque a Ana Tavares, por exemplo, que é da [geração da] década de 1980, também tem uma atuação que é muito "coletivizada". Mas de uma outra maneira, também.

Artista e ao mesmo tempo pesquisador, teórico, professor

VG:

Ser um pesquisador no Brasil é extremamente difícil. Falta financiamento adequado à Pesquisa, o processo de o pós-graduando chegar a ser professor universitário é longo e desgastante. De onde vem esse interesse de percorrer a carreira acadêmica? Um doutorado é um acontecimento. São quatro anos; é penoso, envolve questões psicológicas que a gente pode até resolver não necessariamente no psiquiatra (risos)...

JMB:

Na nutricionista...

VG:

Na nutricionista... 


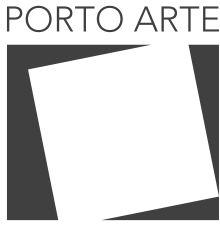

Revista de Artes Visuais

v $25 n .44$

Jul/dez 2020 e-ISSN: 2179-8001

JMB:

Eu acho que isso diz respeito ao meu entendimento de arte. Acho que essa dimensão que eu chamo de metabólica, ou reflexiva, ela é tão constituinte quanto os outros aspectos estruturais da arte, seja do museu, da sala de exposição, seja da obra material. É a possibilidade de leitura, de deglutição, que se encontra na sala de aula, na universidade ou na biblioteca. São ambientes privilegiados para que você exerça esse momento metabólico. Seja de leitura de outros autores, dos seus pares, seja da história da arte, seja da sua própria produção. É uma coisa que eu ainda não elaborei muito a esse respeito. Me interessa, é algo que me passou já pela cabeça. Eu gosto muito de usar essas metáforas do sistema digestivo, da metabolização, ou elaboração ou reflexivo, como isso que acontece para além do que está visível. No momento em que você engole algo, já não está mais operando no campo da visibilidade, mas de uma outra temporalidade que demora horas e horas para você digerir, para você descompactar aquilo que come, que é um processo de desconstrução e de penetração em uma esfera molecular. Então, se você vir uma maçã e imaginar o que acontece com uma maçã dentro do seu organismo, ela é completamente desmembrada e aberta. Então, eu acho que o processo digestivo é um processo analítico. No momento em que ele parece que desconstrói cada célula, cada organização, cada estrutura, para gerar uma outra coisa e dali extrai energia. E isso já acontece na minha graduação, existem insights importantes, existem construções abstratas ou concretas; me dou conta da fertilidade desse momento educativo, que acontece na universidade, passo a me interessar por isso. E daí quando começo a atuar como artista, em 1997, 1998, é a minha primeira exposição Con-fio, e de repente me dou conta de que eu me torno uma espécie de repetidor de uma metodologia de trabalho que eu aprendo na graduação, que o formato expositivo não me fornece as ferramentas necessárias para que eu questione o próprio método. E eu me dou conta de que um mestrado pode ser, justamente, uma volta para a academia, pode ser justamente um recuo crítico em relação a essa temporalidade louca que é a das exposições, em que você é convidado com três meses, no máximo um ano de antecedência, o quão pouco reflexivo é isso. $\mathrm{E}$, de repente, no mestrado eu tive três anos, quatro se for incluir o meu ano como aluno especial, para pensar um assunto. Em qual outro momento do sistema da arte que a gente tem o privilégio de se dedicar a uma questão por tanto tempo? E descompactar isso. E pensar, e estender, e estirar e... Para mim, esse excesso de metáforas que eu uso do campo digestivo tem uma relação com a antropofagia, com uma forma brasileira ou indígena de construção da identidade. Ela passa pelo sistema digestivo mais do que por uma abordagem logocêntrica, de construção dessa identidade. Então, embora isso não seja declarado, para mim é algo que, de uma certa maneira, é como eu também me sinto brasileiro nesse entendimento do processo antropofágico, um processo digestivo. Seja como metáfora, seja como algo concreto. E acho que, sim, esse ambiente acadêmico, para mim, é esse lugar de um recuo crítico, de um recuo digestivo. E, paradoxalmente, é um ambiente muito logocêntrico. Então, não é que eu vou fazer um retiro em algum lugar, que seja de suspensão somente das minhas atividades. Envolve um método - no caso de poéticas, é bem mais flexível - que então possibilita que eu pense um objeto como esse. Eu acho que ele não tem a sua centralidade, acho que ele se utiliza da palavra para pen- 


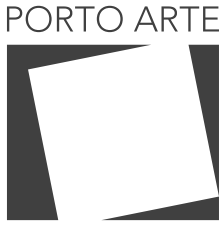

Revista de Artes Visuais

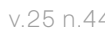

sar, mas eu acho que não é logocêntrico com L maiúsculo. Assim, acho que ele não coloca uma centralidade no discurso. Não como eu sinto. Então, eu acho um privilégio poder ter feito um mestrado, um doutorado, um pós-doc.

\section{VG:}

Você acha que o seu trabalho existiria sem?

JMB:

Não, de forma alguma, de forma alguma. Eu não teria conseguido elaborar. Pelo tempo, pelos autores e pelas discussões. Eu acho que tem algo que me dei conta no mestrado, é como a sala de aula se torna o teu ateliê e teu processo se torna público. Então, você passa a incluir todos esses outros discursos de autores, de orientador que lê o seu texto e dos colegas que estão participando junto com você em uma disciplina de metodologia; de repente tu tens uma complexidade de vozes que te traz um estado de presentidade, porque daí você está no mundo mesmo, você está ali trazendo as suas questões íntimas para uma esfera que é pública, de discussão pública. É como eu vejo a sala de aula, uma estância pública.

VG:

Mesmo a pesquisa? Ela é mais solitária...

JMB:

Eu acho que a pesquisa é muito populada pelos autores que você traz. Ela pode ser solitária nesse sentido concreto; a gente está sozinho, mas a gente está o tempo inteiro em diálogo com diversos autores. E o orientador, a princípio, também, é alguém que está com você o tempo inteiro, por mais que, às vezes, não tanto quanto a gente gostaria. Sempre tem uma carência de orientação dos pós-graduandos. Isso me entusiasma, essa energia desse lugar me entusiasma e me preocupa que a gente esteja diante.... às vezes, eu tenho uma sensação de que é um ambiente ameaçado, atualmente, por tantas instâncias e por tantas questões que a gente tem vivido a ponto de eu questionar se é um lugar que eu vá ficar.

VG:

Como terminar a carreira de artista na universidade?

JMB:

É, me pergunto se isso de fato é possível no Brasil hoje, se isso é viável diante de todo o cenário que a gente está. A universidade pública está muito estranha. Então, às vezes eu tenho uma sensação, poxa, de repente, também sou parte de uma geração que teve uma proximidade, uma geração de artistas que teve uma proximidade com a academia, mas eu não sei se isso é um lugar que vá se manter. Tenho essa dúvida, se a gente não está vendo também o nascimento de outras formas de produção, que daí também não têm mais a ver com a minha geração. 


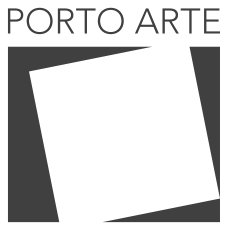

Revista de Artes Visuais

V.25 n. 44
VG:

E que passam pela pesquisa?

JMB:

Não acadêmica. Não necessariamente acadêmica.

VG:

Pode acontecer a pesquisa mas não necessariamente acadêmica?

JMB:

É. Não tão rente à academia. Eu acho que eu tenho, mesmo a Carla, e tantos outros artistas que fizeram mestrado, doutorado... Eu acho que faz parte de uma geração que incluiu a academia de maneira muito determinante nas suas pesquisas. Eu acho fascinante a gente poder ter essa matéria-prima na teoria, nos autores, a forma como se teoriza sobre a aula também. 


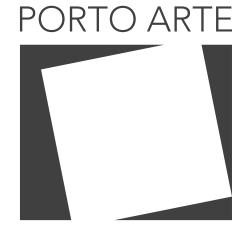

Revista de Artes Visuais

V.25 n. 44 Jul/dez 2020 e-ISSN: 2179-8001

Texto submetido em: 19/08/2020 Texto aprovado em: 22/09/2020 Texto publicado em: 19/12/2020

\section{Vagner Godói}

Pós-doutorando no departamento de História da Universidade Estadual Paulista (Unesp), campus de Franca, e membro colaborador do Centro de Investigação e de Estudos em Belas-Artes da Universidade de Lisboa (CIEBA-FBAUL). Doutor e mestre pelo Programa de Pós-Graduação Interunidades em Estética e História da Arte da Universidade de São Paulo (PGEHA USP). Possui graduação em Design Gráfico pela Unesp, campus de Bauru. Vem estudando a história da Pesquisa em Arte e Design a partir de uma perspectiva pós-estruturalista e dos estudos culturais.

\section{Jorgge Menna Barreto}

Artista e educador. Doutor e mestre em Poéticas Visuais pela ECA-USP. Fez pós-doutorado na Udesc em 2014, onde colaborou com um biólogo e um agrônomo para investigar relações entre o site-specific e a agroecologia, com ênfase em agroflorestas. O pós-doutorado realizado na Liverpool John Moores University (LJMU) resultou no trabalho que será apresentado em 2021 na Bienal de Liverpool. Foi professor no Instituto de Artes da UERJ. Hoje é docente do departamento de arte e do mestrado em arte ambiental e prática social na Universidade da Califórnia Santa Cruz (UCSC). Site do artista: https://jorggemennabarreto.com 